\title{
ResearchArticle
}

\section{Ethnomedical knowledge of plants used by elderly learned and experienced knowledgeable persons in remote villages of Jhansi and Lalitpur districts of Bundelkhand region, India}

\author{
RAJ KUMAR VERMA
}

\begin{abstract}
SUMMARY
The present study deals with traditional knowledge regarding utilization of ethnomedicinal plants for treating various diseases and ailments was collected by direct interviewing elderly learned and experienced knowledgeable resource persons who have traditional knowledge about these ethnomedicinal plants in the remote villages of Jhansi and Lalitpur district of Bundelkhnad, Central India. A total of 68 plant species in 64 genera and 36 families were used traditionally with various plant parts and their combination for the treatment of various ailments and diseases in the studied area. The highest number of ethnomedicinal plants was recorded in families Fabaceae having 12 plants species. Among all the plant habit, tree ( 25 plant species) was found to be the most used plant habit. Methods of preparation fall into eight categories viz., ash, infusion, decoction, extract, juice, paste, powder, and various fresh plant parts used directly. The flora of Jhansi and Lalitpur district of Bundelkhand region has immense pharmaceutical and commercial potential.
\end{abstract}

Key Words : Ethnomedicinal plants, Human ailments, Diseases, Traditional knowledge

\begin{abstract}
How to cite this article : Verma, Raj Kumar (2016). Ethnomedical knowledge of plants used by elderly learned and experienced knowledgeable persons in remote villages of Jhansi and Lalitpur districts of Bundelkhand region, India. Internat. J. Plant Sci., 11 (2): 345-354, DOI: 10.15740/HAS/IJPS/11.2/345-354.
\end{abstract}

Article chronicle : Received : 22.04.2016; Revised : 30.05.2016; Accepted : 26.06.2016 